\title{
The Platelet Count and its Implications in Sickle Cell Disease Patients Admitted for Intensive Care
}

\author{
Durjoy K. Shome, Ahmed Jaradat' ${ }^{1}$, Ahmed I. Mahozi, Ali S. Sinan, Ali Ebrahim, Mohammed Alrahim, Mohammad S. Ebraheem, Eman J. Mansoor², \\ Kameela S. Majed², Sheikh A. Azeez Pasha ${ }^{3}$ \\ Departments of Pathology and ${ }^{1}$ Family and Community Medicine, College of Medicine and Medical Sciences, Arabian Gulf University, Departments of ${ }^{2}$ Pathology and \\ ${ }^{3} \mathrm{CU}$ and Anesthesiology, Salmaniya Medical Complex, Manama, Bahrain
}

\section{Abstract}

Background and Aims: In sickle cell disease (SCD) patients admitted for intensive care, evaluation of platelet counts in different types of sickle cell complications and its prognostic relevance are not well-studied. Illuminating these aspects were the objectives of this study. Materials and Methods: A chart review of 136 adult SCD patients consecutively admitted to our Intensive Care Unit (ICU) was done. The prognosis on day 1 was assessed by Acute Physiology and Chronic Health Evaluation (APACHE II) and multiple organ dysfunction scores (MODS). Receiver operating characteristic (ROC) curves evaluated the ability of platelet counts, MODS, and APACHE II scores to predict survival. Results: The most common types of crises were severe pain $(n=53)$, acute chest syndrome $(n=40)$, and infection $(n=18)$; 17 patients were nonsurvivors. Platelet counts varied widely (range, $\left.19-838 \times 10^{9} / \mathrm{L}\right)$ with thrombocytopenia $(n=30)$ and thrombocytosis $(n=11)$. Counts correlated directly with leukocytes and reticulocytes; inversely with lactate dehydrogenase, APACHE, and MODS scores. Areas under ROC curve for platelets, MODS, and APACHE scores to predict survival were 0.73, 0.85, and 0.93, respectively. Conclusions: In severe sickle cell crisis thrombocytopenia is more common than thrombocytosis. In the ICU, day 1 platelet counts correlate inversely with prognostic scores and are significantly reduced in multi-organ failure and nonsurvivors. A platelet count above $175 \times 10^{9} / \mathrm{L}$ predicts patient survival with high specificity and positive predictive value but lacks sensitivity.

Keywords: Acute physiology, chronic health evaluation II, multi-organ dysfunction score, platelets, sickle cell disease, thrombocytopenia

\section{INTRODUCTION}

The clinical picture of sickle cell disease (SCD) is dominated by complications arising from vaso-occlusive crisis (VOC). VOC is precipitated by complex interactions between sickled erythrocytes, endothelial cells, leukocytes, platelets, and plasma proteins. The role of platelets in these interactions is well documented. ${ }^{[1-6]}$

In the baseline "steady-state," platelets are generally normal to increase in number and functionally hyperactive. ${ }^{[3-6]}$ During sickle cell crisis, platelet counts decline in the initial phases and rise later during recovery. ${ }^{[3,7-10]}$ Thrombocytopenia is rarely reported but may occur with acute splenic sequestration, aplastic crisis with parvovirus B19 infection and fat embolism. ${ }^{[11-17]}$ However, there is little information about platelet counts and their relationship to disease severity and survival in acutely affected sickle cell patients admitted to an intensive care unit (ICU). This is the main reason for carrying

\begin{tabular}{|l|l|}
\hline \multicolumn{3}{|c|}{ Access this article online } \\
\hline Quick Response Code: & Website: \\
& www.ijccm.org \\
\cline { 2 - 2 } & \\
\end{tabular}

out the present study. Our test hypothesis was that platelet counts in SCD crisis correlate significantly with disease severity and outcome.

\section{Materials and Methods}

\section{Study design and input data}

We did a retrospective cross-sectional chart review study of all adult SCD patients (homozygous sickle cell anemia and sickle-beta thalassemia) admitted to our adult ICU during a 1-year period. The inclusion criteria were as follow: (1) a diagnosis of sickle cell anemia (SS) or sickle-beta thalassemia

Address for correspondence: Dr. Durjoy K. Shome, Department of Pathology, College of Medicine and Medical Sciences, Arabian Gulf University, Manama, Bahrain. E-mail: dr.dkshome@gmail.com

This is an open access journal, and articles are distributed under the terms of the Creative Commons Attribution-NonCommercial-ShareAlike 4.0 License, which allows others to remix, tweak, and build upon the work non-commercially, as long as appropriate credit is given and the new creations are licensed under the identical terms.

For reprints contact: reprints@medknow.com

How to cite this article: Shome DK, Jaradat A, Mahozi AI, Sinan AS, Ebrahim A, Alrahim M, et al. The platelet count and its implications in sickle cell disease patients admitted for intensive care. Indian J Crit Care Med 2018;22:585-90. 
on the basis of hemoglobin ( $\mathrm{Hb})$ analysis by high-performance liquid chromatography and (2) availability of a complete blood count (CBC) on day 1 of admission. The study was approved by the Research and Ethics Committees of the participating institutions.

All relevant clinical and laboratory data of patients during their period of ICU stay were documented from case-files and the hospital information system. This included data related to vitals, Glasgow coma score (GCS), blood gas results, electrolytes, hepatic and renal function tests, CBC, coagulation tests, microbiologic cultures and serology, history of chronic disease, and the final diagnosis at the time of ICU discharge or death. Platelet counts at admission (day 1) and the nadir platelet count during ICU stay were recorded.

\section{Definitions}

Diagnostic criteria were employed as follows: thrombocytopenia was defined as a platelet count of $<100 \times 10^{9} / \mathrm{L}$; thrombocytosis as a count $\geq 450 \times 10^{9} / \mathrm{L}$. Acute chest syndrome (ACS) was defined as the appearance of a new pulmonary infiltrate along with chest pain, fever, tachypnea, wheezing, or coughs. ${ }^{[18]}$ Aplastic crisis was diagnosed on the basis of anemia associated with reticulocytopenia. ${ }^{[19]}$ Hyperhemolysis was defined as a sudden fall in the $\mathrm{Hb}$ level with an elevated reticulocyte count above the baseline level. ${ }^{[19]}$

Relevant clinical and laboratory data were used in assessing crisis severity on admission (day 1). This was estimated by two methods: the acute physiology and chronic health evaluation (APACHE II) prognostic score and Multiple Organ Dysfunction estimated by the Marshall score (MODS). ${ }^{[20,21]}$ The APACHE II is based on recording 12 physiologic variables, age and chronic health status; MODS is derived from parameters reflecting the function of six organ systems (respiratory, renal, cardiovascular, hepatic, hematological, and central nervous system). The patient outcomes were assessed by documenting mortality and number of days of ICU stay. Significant multiorgan failure was defined as MODS score $>5$. $^{[22,23]}$

\section{Statistical analysis}

The Pearson correlation coefficient was used to evaluate correlations between platelet counts and other numeric variables and between MODS and APACHE scores. Nonparametric tests (Kruskal-Wallis and Mann-Whitney) were used to investigate differences between groups of patients stratified by their platelet counts; mortality versus recovered patient groups and differences between patient-groups stratified by diagnosis. Logistic and multiple regression analyses were employed to test for the influence of 14 selected clinical and laboratory variables on the admission outcomes (mortality and duration of ICU stay). Receiver operating characteristic (ROC) curves were constructed from the day 1 platelet counts, MODS and APACHE scores of patients and their survival/death outcome data.

\section{RESULTS}

\section{Clinical and laboratory features}

The study population included 136 admissions (124 patients; 52 females and 72 males). Table 1 shows the diagnostic categories. The three most common sickle complications requiring ICU admission were severe pain crisis, ACS, and infection. Together, these comprised $82 \%$ of all cases.

Multiorgan failure was present in 35 patients who had sepsis $(n=8), \operatorname{ACS}(n=13)$, severe pain crises $(n=8)$, hyperhemolysis $(n=2)$, aplastic crisis $(n=2)$, heart failure $(n=1)$, and trauma $(n=1)$. The median platelet count in this group of patients was $76 \times 10^{9} / \mathrm{L}$ as compared to $211 \times 10^{9} / \mathrm{L}$ in the non-MODS group $(P<0.001)$.

Selected laboratory and clinical data are shown in Table 2. Common findings were mild/moderate anemia and leukocytosis, elevated serum bilirubin, and lactate dehydrogenase (LDH). The routine coagulation test profile was characterized by raised prothrombin time and international normalized ratio in the presence of low-normal activated partial thromboplastin

\begin{tabular}{|c|c|c|c|c|c|c|}
\hline Diagnosis/outcome & $\begin{array}{l}\text { Number } \\
\text { of cases }\end{array}$ & $\begin{array}{l}\text { Median platelet } \\
\text { count }\left(\times 10^{9} / L\right)\end{array}$ & $\begin{array}{c}\text { Thrombocytopenia } \\
\left(<100 \times 10^{9} / \mathrm{L}\right), n(\%)^{\dagger}\end{array}$ & $\begin{array}{c}\text { Thrombocytosis (>450 } \\
\left.\times 10^{9} / \mathrm{L}\right), n(\%)^{\dagger}\end{array}$ & $\begin{array}{l}\text { MODS score } \\
\text { (median) }\end{array}$ & $\begin{array}{c}\text { APACHE II } \\
\text { score (median) }\end{array}$ \\
\hline Severe pain crisis & 53 & 177 & $9(17)$ & $6(11)$ & 2.0 & 7.0 \\
\hline Acute chest syndrome & 40 & 196 & $8(20)$ & $1(3)$ & 4.0 & 10.0 \\
\hline Infection/sepsis & 18 & 171 & $5(28)$ & $3(17)$ & 4.0 & 7.5 \\
\hline Pulmonary embolism & 4 & 195 & 0 & 0 & 3.0 & 5.5 \\
\hline Trauma & 4 & 285 & $1(25)$ & 0 & 5.0 & 10.0 \\
\hline Hemolytic crisis & 3 & 89 & $2(67)$ & 0 & 6.0 & 8.0 \\
\hline Aplastic crisis & 2 & 56 & $2(100)$ & 0 & 6.5 & 10.0 \\
\hline Miscellaneous* & 12 & 219 & $3(25)$ & $1(8)$ & 3.0 & 7.0 \\
\hline Total cases & 136 & 187 & $30(22)$ & $11(8)$ & 3.0 & 8.0 \\
\hline Survivors & 119 & 203 & $22(18)$ & $11(9)$ & 3.0 & 8.0 \\
\hline Nonsurvivors & 17 & 125 & $8(47)$ & 0 & 8.0 & 26.0 \\
\hline
\end{tabular}

${ }^{\dagger}$ Represents percentage of the number of cases within the specific diagnosis/outcome group, ${ }^{*}$ Miscellaneous conditions included: cor pulmonale (4), renal failure (3), cerebrovascular event (2), bronchial asthma (2), and cholecystitis (1). APACHE II: Acute Physiology and Chronic Health Evaluation II; MODS: Multiple Organ Dysfunction Syndrome 
Table 2: Laboratory and clinical data (mean \pm standard deviation) in study subjects and groups of sickle cell disease patients stratified by their platelet counts

\begin{tabular}{|c|c|c|c|c|c|}
\hline \multirow[t]{2}{*}{ Observations } & \multirow{2}{*}{$\begin{array}{l}\text { All study } \\
\text { subjects }\end{array}$} & \multicolumn{3}{|c|}{ Platelet count $\left(\times 10^{9} / \mathrm{L}\right)$} & \multirow{2}{*}{$\begin{array}{c}\text { Kruskal-Wallis* } \\
(P)\end{array}$} \\
\hline & & $<100(n=30)$ & $100-450(n=95)$ & $>450(n=11)$ & \\
\hline $\mathrm{Hb}(\mathrm{g} / \mathrm{dL})$ & $8.5 \pm 1.7$ & $7.6 \pm 1.5$ & $8.8 \pm 1.7$ & $8.7 \pm 1.5$ & $<0.01$ \\
\hline Leukocytes $\left(\times 10^{9} / \mathrm{L}\right)$ & $14.5 \pm 8.7$ & $10.5 \pm 7.0$ & $15.0 \pm 8.7$ & $20.9 \pm 9.0$ & $<0.01$ \\
\hline Reticulocytes $\left(\times 10^{12} / \mathrm{L}\right)$ & $0.23 \pm 0.56$ & $0.13 \pm 0.10$ & $0.26 \pm 0.66$ & $0.20 \pm 0.12$ & $<0.01$ \\
\hline APTT (ratio) & $1.2 \pm 0.4$ & $1.3 \pm 0.4$ & $1.2 \pm 0.4$ & $1.1 \pm 0.1$ & NS \\
\hline PT (INR) & $1.4 \pm 0.4$ & $1.5 \pm 0.4$ & $1.4 \pm 0.4$ & $1.3 \pm 0.2$ & NS \\
\hline Fibrinogen (mg/dL) & $444 \pm 191$ & $411 \pm 204$ & $446 \pm 185$ & $521 \pm 209$ & NS \\
\hline D-dimer (U/L) & $11.3 \pm 10.9$ & $15.0 \pm 10.9$ & $10.5 \pm 10.9$ & $9.6 \pm 10.7$ & NS \\
\hline Bilirubin total (umol/L) & $91 \pm 114$ & $130 \pm 157$ & $81 \pm 99$ & $76 \pm 75$ & NS \\
\hline $\operatorname{ALT}(\mathrm{U} / \mathrm{L})$ & $76 \pm 96$ & $98 \pm 94$ & $74 \pm 100$ & $35 \pm 10$ & $<0.001$ \\
\hline Creatinine (umol/L) & $0.9 \pm 0.6$ & $1.03 \pm 0.83$ & $0.83 \pm 0.52$ & $0.7 \pm 0.2$ & NS \\
\hline LDH (U/L) & $1250 \pm 1186$ & $2043 \pm 1395$ & $1089 \pm 1061$ & $528 \pm 377$ & $<0.001$ \\
\hline APACHE II score & $10.2 \pm 7.6$ & $14.2 \pm 8.7$ & $9.3 \pm 7.1$ & $6.3 \pm 2.2$ & $<0.01$ \\
\hline MODS score & $4.1 \pm 3.0$ & $7.2 \pm 2.9$ & $3.35 \pm 2.44$ & $2.5 \pm 2.0$ & $<0.001$ \\
\hline ICU stay (days) & $5.7 \pm 7.7$ & $8.2 \pm 10.7$ & $5.1 \pm 6.8$ & $3.7 \pm 1.2$ & NS \\
\hline
\end{tabular}

*Kruskal-Wallis test for comparison between groups of patients stratified by platelet count. APTT: Activated partial thromboplastin time; PT: Prothrombin time; ALT: Alanine aminotransferase; LDH: Lactate dehydrogenase; APACHE II: Acute Physiology and Chronic Health Evaluation II; MODS: Multiple Organ Dysfunction Syndrome; ICU: Intensive Care Unit; Hb: Hemoglobin; NS: Not significant; INR: International normalized ratio

time ratio, elevated fibrinogen, and marked elevation of D-dimer levels. APACHE scores were calculated in 104 study individuals. There was a significant correlation between the APACHE II and MODS scores $(r=0.78 ; P<0.001)$.

\section{Platelet counts and correlations}

Platelet counts showed wide variation: Ranging from 19 to $838 \times 10^{9} / \mathrm{L}$ (mean, $221 \pm 156 \times 10^{9} / \mathrm{L}$ ). Thrombocytopenia was observed at admission in 30 patients ( $22 \%$ of admissions) and thrombocytosis in $11(8 \%)$. Moreover, 51 patients (38\%) developed thrombocytopenia at some point during their ICU stay. Day 1 and nadir platelet counts were strongly correlated $(r=0.9, P<0.001)$. Platelet counts at admission also correlated moderately with MODS scores $(r=-0.43 ; P<0.001)$ and weakly with APACHE II $(r=-0.32$, $P=0.001)$. Figure 1 depicts the correlation trend between platelet counts and MODS scores.

Highly significant differences were observed between the thrombocytopenia group and the groups of patients with normal or increased platelet counts [Table 2]. Thrombocytopenic patients showed significantly lower $\mathrm{Hb}$, leukocytes (white blood cell [WBC]), and reticulocytes; higher bilirubin, alanine aminotransferase (ALT), APACHE, and MODS scores. Significant differences between patients with normal platelet count and thrombocytosis were also noted in relation to several laboratory variables (WBC, ALT, and LDH), but the disease severity scores were not significantly different.

Thrombocytopenia was present within all diagnostic categories including VOC with severe pain $(n=9)$, ACS $(n=8)$, and sepsis $(n=5)$. Two patients with hyper-hemolysis and both patients in aplastic crisis also presented with thrombocytopenia. On the other hand, patients with thrombocytosis were admitted with severe pain $(n=8)$ or inflammation-associated etiology

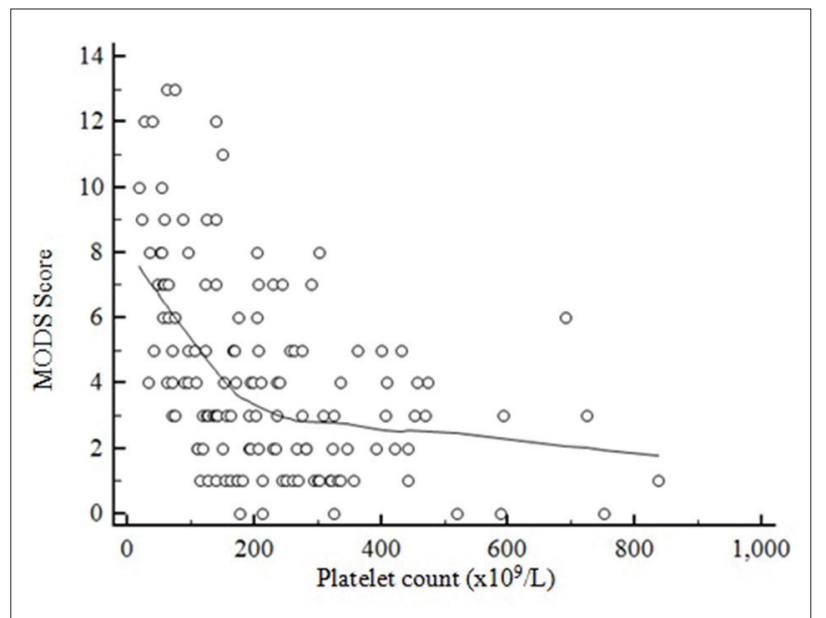

Figure 1: Correlation between platelet counts and multiple organ dysfunction scores in sickle cell patients admitted to the Intensive Care Unit. The trend line is shown

$(n=3)$. However, platelet count variations between the eight diagnostic categories did not reach statistical significance.

Specific mention of hydroxyurea (HU) treatment was available in $6 / 59$ patients. None of the patients on HU were thrombocytopenic (median platelets $269 \times 10^{9} / \mathrm{L}$ ). Spleen size was recorded in 25 patients; platelet counts in 8 patients with splenomegaly was significantly reduced versus 17 with noted "no splenomegaly" (Mann-Whitney, $P<0.05$ ).

\section{Patient outcomes}

There were 17 nonsurvivors (12.5\% of the study population). These patients were admitted with sepsis/infection $(n=9)$, ACS $(n=4)$, severe pain $(n=2)$, aplastic crisis $(n=1)$, and pulmonary hypertension with heart failure $(n=1)$. The platelet 
count at admission [Table 1] was significantly lower in the mortality group compared to patients who survived $(P=0.002$, Mann-Whitney test). The distribution of platelet counts in these two groups of patients is shown in Figure 2. Lower reticulocyte count $(P<0.01)$, higher D-dimer $(P=0.02)$, bilirubin, creatinine, LDH, APACHE, and MODS scores $(P<0.001$, respectively) also characterized the group of nonsurvivors.

Durations of patients' stay in the ICU [Table 2] correlated moderately with MODS scores $(r=0.36, P<0.001)$ and weakly with day 1 as well as nadir platelet counts and APACHE scores. Multiple regression analysis revealed that GCS $(P<0.001)$ and arterial oxygen saturation $(P<0.01)$ were independent predictors of the duration of stay. Results of ROC curve analyses of the platelet count, MODS and APACHE scores as predictors of survival are shown in Table 3 and Figure 3. Importantly, the cutoff value of platelet count $175 \times 10^{9} / \mathrm{L}$ showed high specificity and positive predictive value (PPV) for survival outcome comparable to both MODS and APACHE scores but weak sensitivity and negative predictive value [negative predictive value; Table 3 ].

\section{DISCUSSION}

A CBC is probably the most commonly done laboratory investigation in sickle cell patients in the hospital. However, there is little information about frequencies of platelet-count abnormalities; clinical correlates in different types of sickle

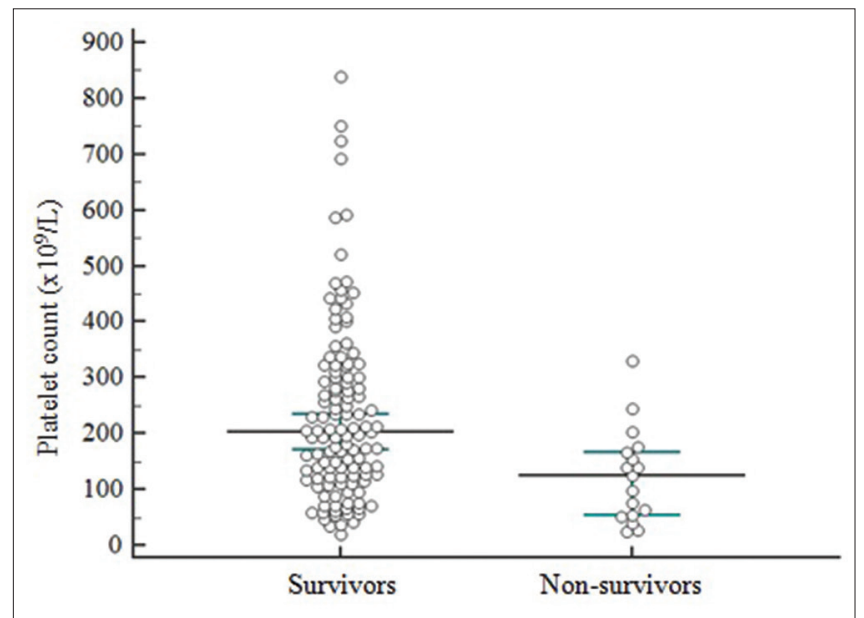

Figure 2: Platelet counts in survivor and nonsurvivor groups of sickle cell patients admitted for intensive care. Horizontal bars represent median values with $95 \%$ confidence intervals cell crisis and prognostic significance of platelet counts in these severely sick patients in the ICU setting. These were the primary reasons for doing this study.

\section{Platelet counts correlate with prognostic scores, clinical} course, and outcome

We found that in the ICU, abnormal platelet counts are relatively common in sickle cell patients suffering from different types of complications. Unlike platelet counts reported in the steady state, thrombocytopenia was more frequent than thrombocytosis. Platelet numbers correlated significantly with laboratory parameters indicative of organ dysfunction and with prognostic scores. In published studies limited to ACS cases, a platelet count $<200 \times 10^{9} / \mathrm{L}$ was found to be an independent predictor of respiratory failure and neurologic complications; thrombocytopenia preceded a rapidly progressive course and was its sole predictor. ${ }^{[18,24]}$ Similarly, in VOC, it was reported that thrombocytopenia may be associated with markedly elevated LDH and a severe course. ${ }^{[25]}$

In contrast to platelet counts in crisis, thrombocytosis is a common observation in steady-state SCD. ${ }^{[3-6]}$ The prognostic implication of elevated baseline platelet counts is debatable with no conclusive evidence of its associations with disease severity or complications. ${ }^{[4]}$ The literature is silent on the question of thrombocytosis in sickle cell crises and its relevance to outcome. Findings in our study demonstrate that

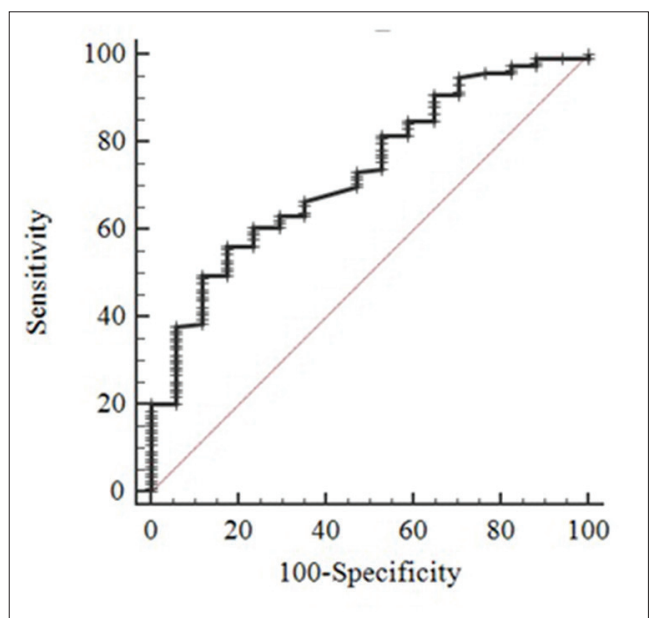

Figure 3: Receiver operating characteristic curve of the platelet count as predictor of survival in sickle cell disease patients admitted to the Intensive Care Unit (area under curve $=0.73$ )

Table 3: Receiver operated characteristic curve analyses of the platelet count, multiple organ dysfunction syndrome and Acute Physiology and Chronic Health Evaluation II scores as survival predictors

\begin{tabular}{|c|c|c|c|c|c|c|c|}
\hline $\begin{array}{l}\text { Variables (number } \\
\text { of cases) }\end{array}$ & AUC & $\begin{array}{l}\text { Youden } \\
\text { index }\end{array}$ & $\begin{array}{l}\text { Associated } \\
\text { cut-off value }\end{array}$ & Specificity (\%) & Sensitivity (\%) & PPV (\%) & NPV (\%) \\
\hline Platelet count (136) & 0.73 & 0.387 & $>175 \times 10^{9} / \mathrm{L}$ & 82 & 56 & 96 & 21 \\
\hline MODS score (136) & 0.85 & 0.647 & $\leq 5$ & 82 & 82 & 97 & 40 \\
\hline Apache II score (104) & 0.93 & 0.768 & $\leq 17$ & 93 & 83 & 98 & 63 \\
\hline
\end{tabular}

AUC: Area under curve; PPV: Positive predictive value; NPV: Negative predictive value; MODS: Multiple Organ Dysfunction Syndrome 
higher platelet counts during crises are linked to lower disease severity scores and predict higher survival chance.

\section{Receiver operating characteristic curve analyses}

The APACHE II score performed best as a predictor of survival with a cutoff score of 17 . The calculation of APACHE scores requires multiple data inputs whereas the platelet count is a readily available indicator with comparable specificity and PPV for predicting survival although its sensitivity is poor.

\section{Mechanisms contributing to platelet-count alterations}

The pathogenesis of thrombocytopenia in SCD crises is multifactorial. In our study, direct correlations of platelet counts with WBC and reticulocytes suggest that compromised marrow function is a contributory factor. A production-defect could result from vaso-occlusive marrow infarction or sepsis. Second, sickle cell-endothelial interaction results in coagulation factor activation and a state of compensated disseminated intravascular coagulation with platelet consumption. This situation is aggravated in crisis..$^{[1,26-29]}$ Thrombocytopenia could be a consequence of HU therapy, although in this study all patients who were taking this medication had normal platelet counts.

Finally, genetic factors may be linked to the relatively high frequency of thrombocytopenia in our study population. Common genetic associations of SCD in our geographic regions such as the Arab-Indian haplotype, alpha thalassemia, and high $\mathrm{HbF}$ levels, are linked to more frequent splenomegaly and hypersplenism compared to African patients. ${ }^{[13,30-32]}$

Autopsy examination of tissues and cytology of bronchial fluid have shown that marrow/fat embolism is a common etiologic factor in SCD crisis and could progress to multi-organ failure. ${ }^{[17,18,33-36]}$ In ACS, pulmonary vessels may be occluded by emboli or by platelet thrombi leading to thrombocytopenia. ${ }^{[33,37]}$ Occasionally, the manifestations of marrow/fat emboli may resemble those seen in thrombotic thrombocytopenic purpura (TTP). Very high $\mathrm{LDH}$, leukoerythroblastic blood picture, thrombocytopenia, schistocytosis, and multiorgan failure are typically seen. ${ }^{[34,36,38]}$ We have previously reported a subgroup of SCD patients who presented with these features and recovered after plasmapheresis. ${ }^{[29]}$ Only one of the patients in the present study had TTP-like features. This condition may be under-diagnosed in the absence of a rigorous peripheral smear examination in all cases presenting with thrombocytopenia.

SCD is also a chronic inflammatory condition in which raised levels of cytokines such as IL-1 $\beta$ and IL- 6 may produce a reactive thrombocytosis. ${ }^{[10]}$ Functional asplenia may also be a contributory factor. ${ }^{[10,39]}$ Finally, since platelet counts may rise during recovery from crisis, ${ }^{[10]}$ our patients who had thrombocytosis at admission were possibly in early recovery though symptomatic. This would also explain good outcomes in this group.

\section{Limitations of the study}

A major limitation of this study is that it is retrospective. Serial measurements of platelet counts noting the magnitude of change from their steady-state values in patients would provide further insight into the dynamics of platelet-count alterations and their implications. Our observations require validation in a larger group of patients.

\section{Conclusions}

This study presents a cross-section of sickle cell patients in severe crisis in an intensive care setting and demonstrates the value of the platelet count as a marker of disease severity and predictor of outcome in these critically sick patients. Platelet numbers correlate with clinical and laboratory indicators of disease severity. Thrombocytopenia is significantly more common in patients with multiorgan failure and nonsurvivors. A cutoff platelet count of $175 \times 10^{9} / \mathrm{L}$ predicts survival with high specificity and PPV. MODS and APACHE II scores perform better due to higher sensitivity; but the value of the platelet count, in addition to its diagnostic implications, lies in its simplicity as a prognosticator.

The pathogenesis and clinical expression of SCD crisis is complex and has the potential of rapid progression to a fatal outcome. A simple scrutiny of the CBC for the presence of thrombocytopenia readily identifies a subgroup of patients with poorer prognosis who would benefit from more stringent management protocols.

\section{Financial support and sponsorship}

Nil.

\section{Conflicts of interest}

There are no conflicts of interest.

\section{RefEREnCes}

1. Pakbaz Z, Wun T. Role of the hemostatic system on sickle cell disease pathophysiology and potential therapeutics. Hematol Oncol Clin North Am 2014;28:355-74.

2. Kuypers FA. Hemoglobin s polymerization and red cell membrane changes. Hematol Oncol Clin North Am 2014;28:155-79.

3. Freedman ML, Karpatkin S. Elevated platelet count and megathrombocyte number in sickle cell anemia. Blood 1975;46:579-82.

4. Okpala I. Steady-state platelet count and complications of sickle cell disease. Hematol J 2002;3:214-5.

5. Kenny MW, George AJ, Stuart J. Platelet hyperactivity in sickle-cell disease: A consequence of hyposplenism. J Clin Pathol 1980;33:622-5.

6. Westwick J, Watson-Williams EJ, Krishnamurthi S, Marks G, Ellis V, Scully MF, et al. Platelet activation during steady state sickle cell disease. J Med 1983;14:17-36.

7. Gordon PA, Breeze GR, Mann JR, Stuart J. Coagulation fibrinolysis in sickle-cell disease. J Clin Pathol 1974;27:485-9.

8. Alkjaersig N, Fletcher A, Joist H, Chaplin H Jr. Hemostatic alterations accompanying sickle cell pain crises. J Lab Clin Med 1976;88:440-9.

9. Billett HH, Nagel RL, Fabry ME. Evolution of laboratory parameters during sickle cell painful crisis: Evidence compatible with dense red cell sequestration without thrombosis. Am J Med Sci 1988;296:293-8.

10. De Franceschi L, Cappellini MD, Olivieri O. Thrombosis and sickle cell disease. Semin Thromb Hemost 2011;37:226-36.

11. Allen U, MacKinnon H,ZipurskyA, Stevens M. Severe thrombocytopenia in sickle cell crisis. Pediatr Hematol Oncol 1988;5:137-41.

12. Rowley PT, Jacobs M. Hypersplenic thrombocytopenia in sickle cell-bata thalassemia. Am J Med Sci 1972;264:489-93.

13. Mallouh AA, Salamah MM. Hypersplenism in homozygous sickle-cell disease in Saudi Arabia. Ann Trop Paediatr 1985;5:143-6. 
14. Casey JR, Kinney TR, Ware RE. Acute splenic sequestration in the absence of palpable splenomegaly. Am J Pediatr Hematol Oncol 1994;16:181-2.

15. Koduri PR. Acute splenic sequestration crisis in adults with sickle cell anemia. Am J Hematol 2007;82:174-5.

16. Goldstein AR, Anderson MJ, Serjeant GR. Parvovirus associated aplastic crisis in homozygous sickle cell disease. Arch Dis Child 1987;62:585-8.

17. Hutchinson RM, Merrick MV, White JM. Fat embolism in sickle cell disease. J Clin Pathol 1973;26:620-2.

18. Vichinsky EP, Neumayr LD, Earles AN, Williams R, Lennette ET, Dean D, et al. Causes and outcomes of the acute chest syndrome in sickle cell disease. National Acute Chest Syndrome Study Group. N Engl J Med 2000;342:1855-65.

19. Ballas SK, Kesen MR, Goldberg MF, Lutty GA, Dampier C, Osunkwo I, et al. Beyond the definitions of the phenotypic complications of sickle cell disease: An update on management. ScientificWorldJournal 2012;2012:949535.

20. Knaus WA, Draper EA, Wagner DP, Zimmerman JE. APACHE II: A severity of disease classification system. Crit Care Med $1985 ; 13: 818-29$

21. Marshall JC, Cook DJ, Christou NV, Bernard GR, Sprung CL, Sibbald WJ, et al. Multiple organ dysfunction score: A reliable descriptor of a complex clinical outcome. Crit Care Med 1995;23:1638-52.

22. Sauaia A, Moore EE, Johnson JL, Ciesla DJ, Biffl WL, Banerjee A, et al. Validation of postinjury multiple organ failure scores. Shock 2009;31:438-47.

23. Minei JP, Cuschieri J, Sperry J, Moore EE, West MA, Harbrecht BG, et al. The changing pattern and implications of multiple organ failure after blunt injury with hemorrhagic shock. Crit Care Med 2012;40:1129-35.

24. Chaturvedi S, Ghafuri DL, Glassberg J, Kassim AA, Rodeghier M, DeBaun MR, et al. Rapidly progressive acute chest syndrome in individuals with sickle cell anemia: A distinct acute chest syndrome phenotype. Am J Hematol 2016;91:1185-90.

25. Gardner K, Thein SL. Super-elevated LDH and thrombocytopenia are markers of a severe subtype of vaso-occlusive crisis in sickle cell disease. Am J Hematol 2015;90:E206-7.

26. Whelihan MF, Lim MY, Mooberry MJ, Piegore MG, Ilich A, Wogu A, et al. Thrombin generation and cell-dependent hypercoagulability in sickle cell disease. J Thromb Haemost 2016;14:1941-52.

27. Buseri FI, Jeremiah ZA, Shokunbi WA. Plasma levels of some blood coagulation parameters in Nigerian homozygous sickle cell patients (HbSS) in steady state. Hematology 2006;11:375-9.

28. Ataga KI, Key NS. Hypercoagulability in sickle cell disease: new approaches to an old problem. ASH Education Program Book. 2007:91-6.

29. Shome DK, Ramadorai P, Al-Ajmi A, Ali F, Malik N. Thrombotic microangiopathy in sickle cell disease crisis. Ann Hematol 2013;92:509-15

30. Alsultan A, Alabdulaali MK, Griffin PJ, Alsuliman AM, Ghabbour HA, Sebastiani P, et al. Sickle cell disease in Saudi Arabia: The phenotype in adults with the Arab-Indian haplotype is not benign. Br J Haematol 2014;164:597-604

31. Serjeant GR, Serjeant BE. Sickle Cell Disease. $3^{\text {rd }}$ ed. Oxford: Oxford University Press; 2001. p. 149-69.

32. Kar BC, Satapathy RK, Kulozik AE, Kulozik M, Sirr S, Serjeant BE, et al. Sickle cell disease in Orissa state, India. Lancet 1986;2:1198-201.

33. Anea CB, Lyon M, Lee IA, Gonzales JN, Adeyemi A, Falls G, et al. Pulmonary platelet thrombi and vascular pathology in acute chest syndrome in patients with sickle cell disease. Am J Hematol 2016;91:173-8.

34. Dang NC, Johnson C, Eslami-Farsani M, Haywood LJ. Bone marrow embolism in sickle cell disease: A review. Am J Hematol 2005;79:61-7.

35. Godeau B, Schaeffer A, Bachir D, Fleury-Feith J, Galacteros F, Verra F, et al. Bronchoalveolar lavage in adult sickle cell patients with acute chest syndrome: Value for diagnostic assessment of fat embolism. Am J Respir Crit Care Med 1996;153:1691-6.

36. Gangaraju R, Reddy VV, Marques MB. Fat embolism syndrome secondary to bone marrow necrosis in patients with hemoglobinopathies. South Med J 2016;109:549-53.

37. Manci EA, Culberson DE, Yang YM, Gardner TM, Powell R, Haynes J Jr., et al. Causes of death in sickle cell disease: An autopsy study. Br J Haematol 2003;123:359-65.

38. Ataga KI, Orringer EP. Bone marrow necrosis in sickle cell disease: A description of three cases and a review of the literature. Am J Med Sci 2000;320:342-7.

39. Araneda M, Krishnan V, Hall K, Kalbfleisch J, Krishnaswamy G, Krishnan K. Reactive and clonal thrombocytosis: Proinflammatory and hematopoietic cytokines and acute phase proteins. South Med J 2001;94:417-20 